\title{
Aspectos da biologia reprodutiva de fêmeas de Etropus longimanus Norman, 1933 (Bothidae) da região de Cabo Frio, Rio de Janeiro. 1. Tamanho da primeira maturação, tipo e época de desova
}

\author{
Adriana Miguel SAAD*1 \& Eduardo FAGUNDES NETTO ${ }^{2}$ \\ ${ }^{1}$ Universidade Santa Úrsula \\ (Rua Fernando Ferrari, 75 - Botafogo, 22231-040, Rio de Janeiro, RJ, Brasil) \\ ${ }^{2}$ Instituto de Estudos do Mar Almirante Paulo Moreira (IEAPM) \\ (Rua Kioto, 253, 28910-000, Arraial do Cabo, RJ, Brasil)
}

- Abstract: As part of upwelling ecosystem project of the Cabo Frio region, 653 female of $E$. longimanus were obtained by monthly sampling from November 1986 to October 1988. Histological analyses were done in order to verify the type of spawning. Mean size at first spawning and the spawning season was determined. The results indicate that mean size at first maturation is $75 \mathrm{~mm}$ standard length and all females were ready for reproduction at $95 \mathrm{~mm}$. Multiple spawning for the species was estimated, occurring from end of spring until the beginning of Fall, with peak spawning summer at water temperature between 13.2 and $18.7^{\circ} \mathrm{C}$ (upwelling period in the region).

- Descriptors: Spawning, Spawing seasons, Reproductive behaviour, Reproduction, Sexual maturity, Etropus longimanus, Upwelling, Cabo Frio: RJ, Brazil.

- Descritores: Desova, Época de desova, Comportamento reprodutivo, Reprodução, Maturidade sexual, Etropus longimanus, Ressurgência, Cabo Frio: RJ, Brasil.

\section{Introdução}

A regiāo de Cabo Frio, localizada à nordeste do Estado do Rio de Janeiro, apresenta, devido a conjunçāo de fatores geográficos, meteorológicos e hidrológicos, a particularidade do fenômeno da ressurgência.

Os estudos sobre a ictiofauna demersal deste ecossistema indicaram que Etropus longimanus é uma espécie abundante nesta regiāo, ocorrendo em todas as fases de seu ciclo de vida.

Etropus longimanus Norman, 1933 é uma das menores espécies de linguados da famf́lia Bothidae. São freqüentemente capturados por redes de arrasto utilizadas na pesca comercial sendo, entretanto, destinados à "misturas ou rejeitos". Beaumariage (1968) relata que as espécies do gênero, encontradas na costa atlântica dos Estados Unidos da América, sāo utilizadas por indústrias de ração para animais. Leslie \& Stewart (1986) descreveram uma espécie nova de Etropus na costa atlântica dos EUA, citando que, até então, eram

$\overline{(*) \text { Bolsista }}$ do CNPq. reconhecidas oito espécies do gênero distribuídas por toda essa área. Etropus longimanus, no entanto, limita-se às costas do Brasil ę Argentina (Carvalho et al., 1968).

Kawakami \& Amaral (1983) verificaram que $E$. longimanus apresenta hábitos bentônicos, sendo o seu regime alimentar composto, principalmente, por anelídeos poliquetos. Peres et al. (1991) verificaram que $E$. longimanus no litoral norte do Estado de São Paulo desova neste local, pois foram observados, em cortes histológicos de ovários maduros, vários folículos hidratados e folículos pós-ovulatórios.

Este trabalho tem por objetivo estimar o tamanho médio da primeira maturação gonadal, o tipo de desova e delimitar a época de desova, relacionando-a com a ocorrência de ressurgência na regiāo.

\section{Material e métodos}

Durante o período de novembro de 1986 a outubro de 1988 foram realizadas coletas mensais na região de Cabo 
Frio (latitude $23^{\circ} \mathrm{S}$ e longitude $41^{\circ} \mathrm{W}$ ), ao longo das is 6 batas de 30, 45 e $60 \mathrm{~m}$ (Fig. 1), a bordo do navio "Sub-Oficial Oliveira", do Instituto de Estudos do Mar Almirante Paulo Moreira (IEAPM).

$O$ instrumento de pesca utilizado foi uma rede de arrasto de porta do tipo "otter trawl", com comprimento de $10 \mathrm{~m}$ de tralha inferior de boca e $8 \mathrm{~m}$ de tralha superior da boca, manga com malha de 2,5 e $2,0 \mathrm{~cm}$, saco com malha de $1 \mathrm{~cm}$ (medidas entre nós adjacentes) e portas, medindo $1,10 \mathrm{~m} \times 0,60 \mathrm{~m}$. Cada arrasto teve duração de $20 \mathrm{~min}$, com velocidade de 2 nós. Além das amostragens da ictiofauna foram realizadas coletas de água junto ao fundo, para deteminação da temperatura e salinidade, utilizando-se garrafa de Nansen com termômetro de inversāo e termosalinômetro do tipo Beckman.

De cada exemplar de $E$. longimanus obteve-se dados sobre comprimento padrão (Ls), peso total (Wt), sexo, estádio de maturação gonadal, segundo Vazzoler (1981), e peso das gônadas $(\mathrm{Wg})$. Foram examinadas porçōes de 30 ovários em diferentes estádios de maturação, submetidas às técnicas histológicas de rotina, coradas com hematoxilina-eosina. Para estimativa do tamanho médio da primeira maturação sexual foi adotada a metodologia descrita por Vazzoler (op. cit.). A transformação linear dos dados foi realizada segundo Nascimento \& Peret (1986). A época de desova foi determinada através da análise da distribuição mensal da freqüência relativa dos estádios de maturação gonadal e da variação mensal dos valores da relação gonadossomática (RGS), expressa pela razâo entre o peso dos ovários e o peso total multiplicado por 100. Foram confrontadas as variações temporais da RGS e dos valores médios da temperatura, a fim de comparar o comportamento dessas duas variáveis (Agostinho, 1979). As distribuiçōes mensais de frequê̂ncia das classes de comprimento padrão, normalizadas por LOG $(X+1)$, foram analisados quanto a ocorrência temporal de exemplares nas fases jovem e adulta, na regiâo. O tipo de desova foi estimada com base no tipo de desenvolvimento ovocitário, verificado a partir das análises histologicas de ovários maduros e com indícios de desova (Chaves, 1988).

\section{Resultados e discussão}

Para as 653 fêmeas de $E$. longimanus da região de Cabo Frio, o comprimento padrão médio da primeira maturação $\left(\mathrm{L}_{\mathrm{s}} \mathrm{m}\right)$ foi de $75 \mathrm{~mm}$ e o comprimento padrāo médio em que todas estão aptas à reprodução (Ls100\%) foi de $95 \mathrm{~mm}$ (Fig. 2).

Vazzoler et al. (1989) encontraram para fêmeas de $E$. longimanus, do litoral de Sāo Paulo, $90 \mathrm{~mm}$ e $130 \mathrm{~mm}$, para o comprimento total médio da primeira maturação e o comprimento total médio em que todos estão aptos à reproduçāo, respectivamente. Tendo em vista que foram utilizadas medidas de Ls e Lt, as diferenças entre os valores por nós estimados e aqueles obtidos por Vazzoler et al., (op. cit.) parecem não ser representativas.

Segundo Nikolsky (1963) a melhoria no suprimento alimentar conduz a um aumento na taxa de crescimento e, conseqüentemente, a uma antecipação do tamanho da primeira maturação.

Desse modo, o suprimento alimentar nas duas áreas consideradas parece ser eqüivalente, o que é coerente, uma vez que as condiçōes oceanográficas prevalecentes do fundo, nessas duas áreas são similares (Castro Filho et al., 1987).

Com base nos trabalhos de Isaac-Nahum et al. (1983) e Chaves (1988), foram consideradas seis fases no desenvolvimento ovocitários desta espécie. A primeira fase $\hat{e}$ denominada de ovogônia, sendo representada pelas células de menores diâmetros, agrupadas em ninhos junto à lamela, caracterizadas principalmente pelo grande volume nuclear, ocupando quase que toda a célula, contendo um ínico nucléolo. Esta fase nāo foi encontrada nos cortes aqui analisados, uma vez que foram utilizados apenas ovários maduros e com indícios de desova.

$\mathrm{Em} E$. longimanus foram observados ov6citos a partir da fase II, designados como estoque de reserva, sem estruturas vitelogênicas. Estes estāo presentes em todas as fases do desenvolvimento ovariano, apresentando um núcleo grande e central, com aproximadamente quatro nucléolos na periferia nuclear, e um citoplasma fortemente basofilo (Fig. 3). A fase III é caracterizada pelo início da deposiçāo de vitelo lipídico no citoplasma, que, nesta espécie, ocorre ao redor do núcleo (Fig. 4). A fase IV é caracterizada pela presença de vitelo lipídico e protéico no citoplasma dos folículos ovarianos. Nesta espécie observa-se que a deposição protéca inicia-se na região cortical citoplasmática. Ainda na fase IV foram visualizadas, com maior nitidez, as camadas envoltórias (membrana vitelina e células foliculares), que circundam os ovócitos externamente (Fig. 5). $\mathrm{Na}$ fase $\mathrm{V}$ os folículos ovarianos apresentam vitelogênese completa, ou seja, o citoplasma apresenta-se completamente preenchido por grânulos lipoprotéicos e o núcleo irregular com tendências migratórias (Fig. 6). Na fase VI os folículos ovarianos sofrem uma hidratação pré-ovulatória, onde observa-se uma migração nuclear para um dos polos e no polo oposto o início da homogeneização do citoplasma, aparecendo nos cortes como uma massa rosa única (Fig. 7). Segundo Chaves (1989) esta hidratação tem origem na transferência do líquido da circulação sangüínea da fêmea até o gameta em desenvolvimento promovendo coalescência dos grânulos de vitelo, aparecendo nos cortes histológicos como uma massa rosa homogeneizada. Após vasto estudo Chaves (1988) observou esta hidratação somente em espécies que habitam ambiente marinho, sugerindo que este fator pode estar mais relacionado ao meio do que ao caráter sistemático.

Os cordōes de células foliculares que permaneceram nos ovários após a desova, denominados de folículos pós-ovulatórios, foram observados em ovários com indícios de desova (Fig. 7).

Após as análises dos cortes histológicos de ovários maduros e com indícios de desova foi constatado um desenvolvimento sincrônico em mais de dois lotes ovocitários (Wallace \& Selman, 1981) pois foram observados, em um mesmo corte, ovócitos nas fases II, III, IV, V, VI e folículos pós ovulatórios (Fig. 7), sugerindo que E. longimanus apresenta desova múltipla. 


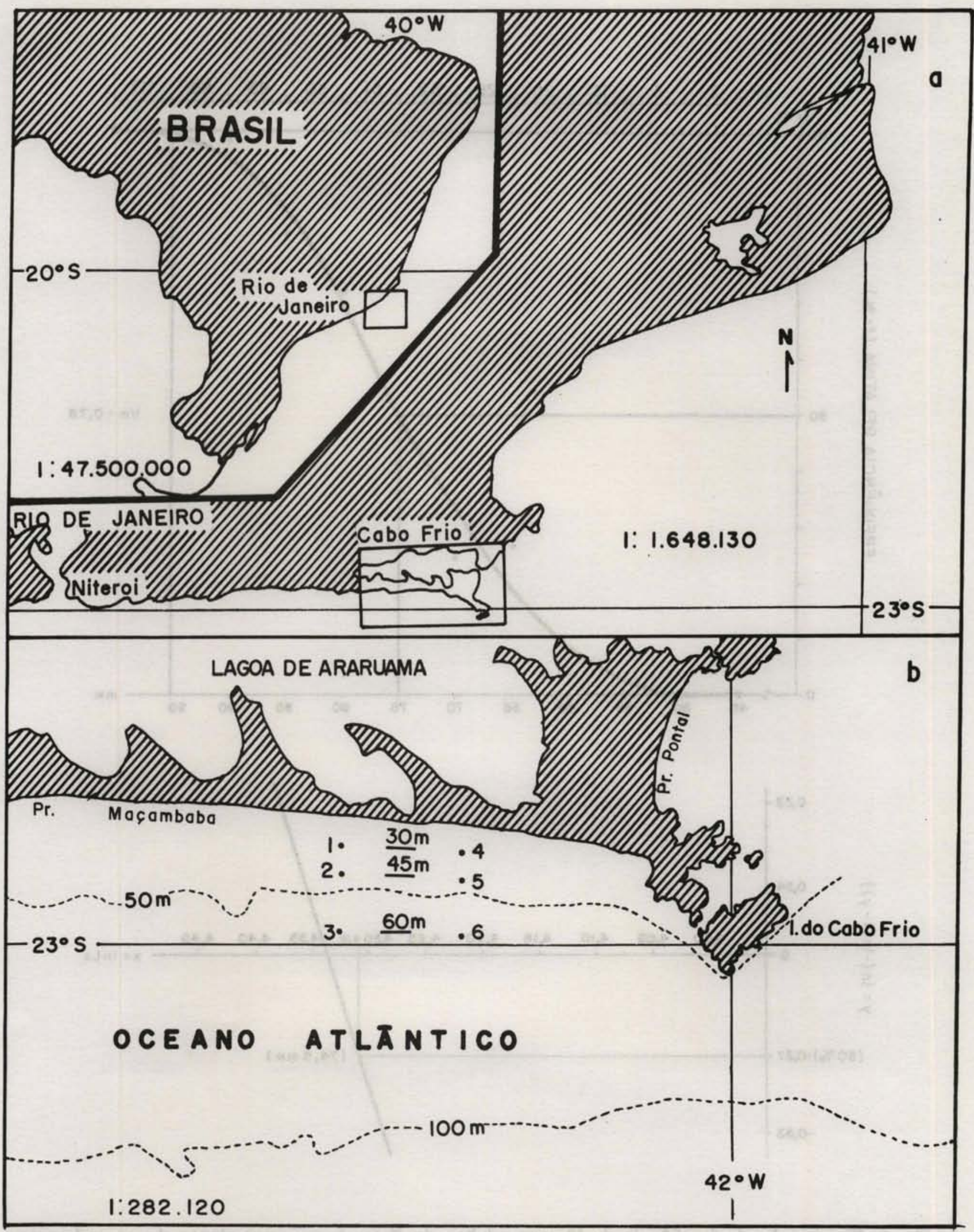

Fig. 1. $a=$ Mapa da região estudada, $b=$ Localização das estações de coleta $(30,45$ e $60 \mathrm{~m})$ e pontos de amostragem dos fatores físico-químicos (1-6). 


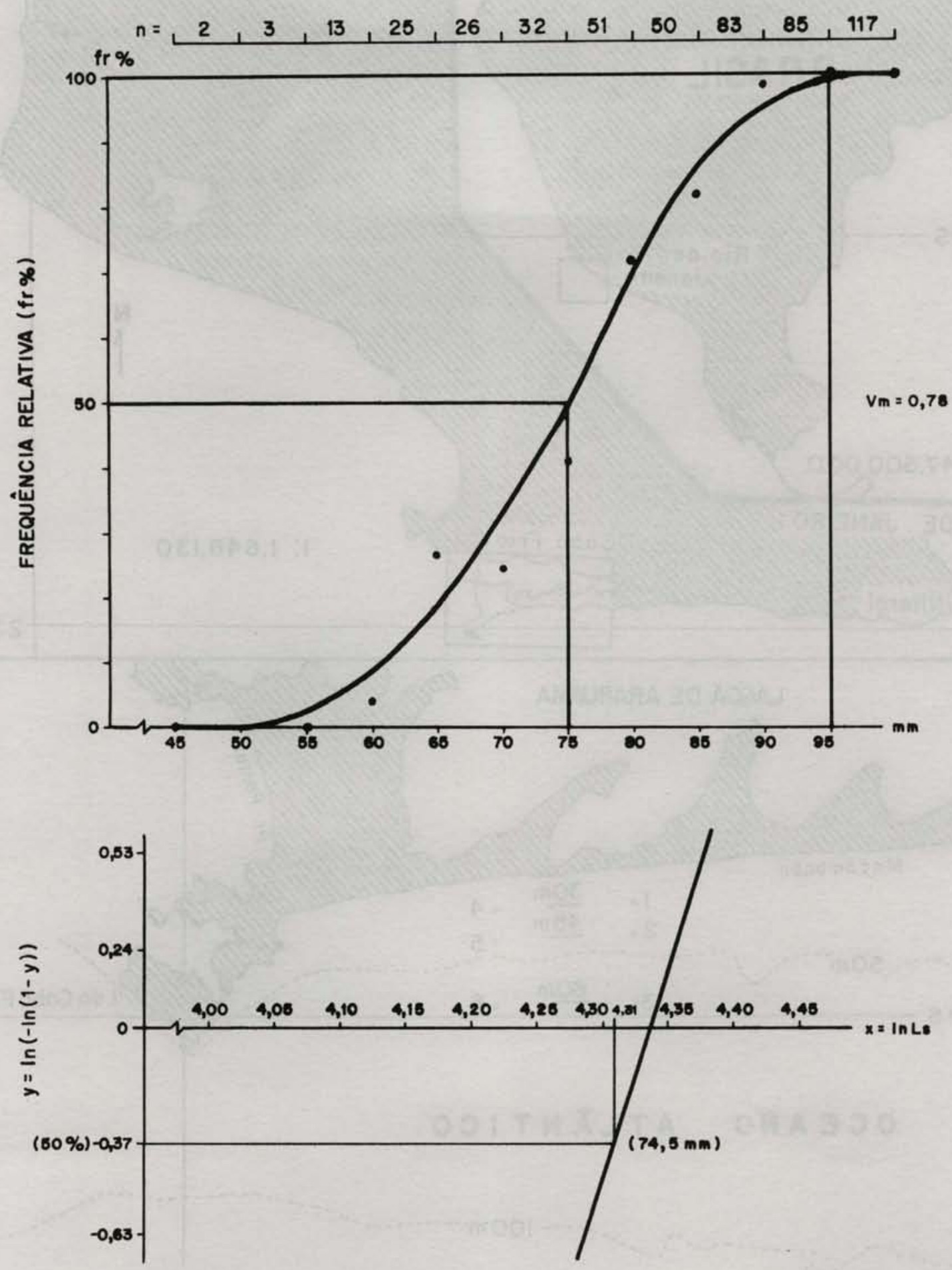

Fig. 2. Distribuição de frequaência de fêmeas adultas de $E$. longimanus por classe de comprimento padrão (Ls) e transformação linear das variáveis, para o período de novembro de 1986 a outubro de 1988. $(\mathrm{Nm}=$ velocidade de maturação). 


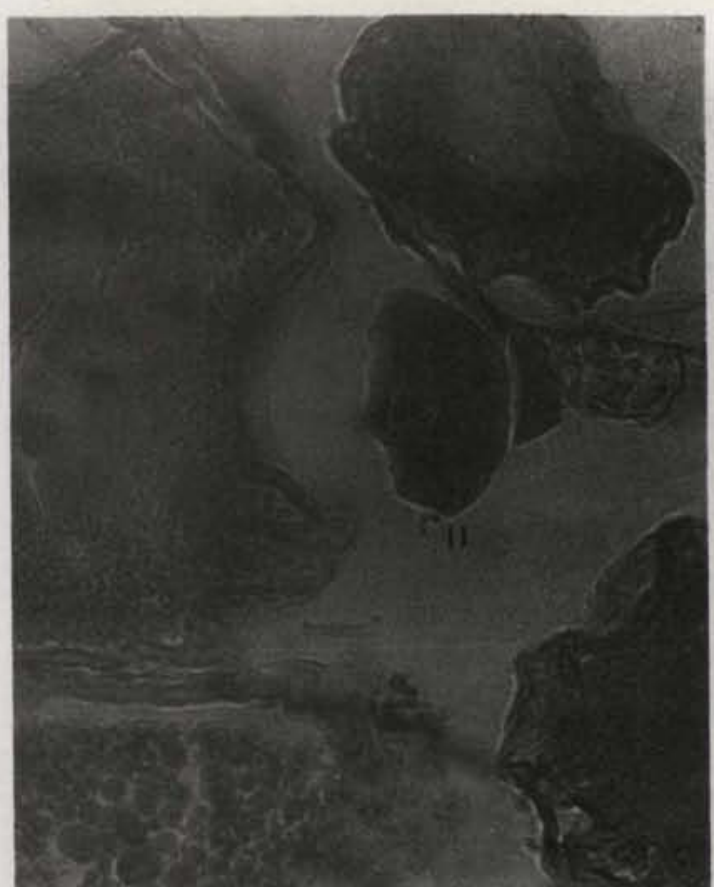

Fig. 3. II = ovócito de estoque de reserva. $\mathrm{N}=$ núcleo; $\mathrm{Nc}=$ nucléolos; $\mathrm{C}=$ cltoplasma (15x10).

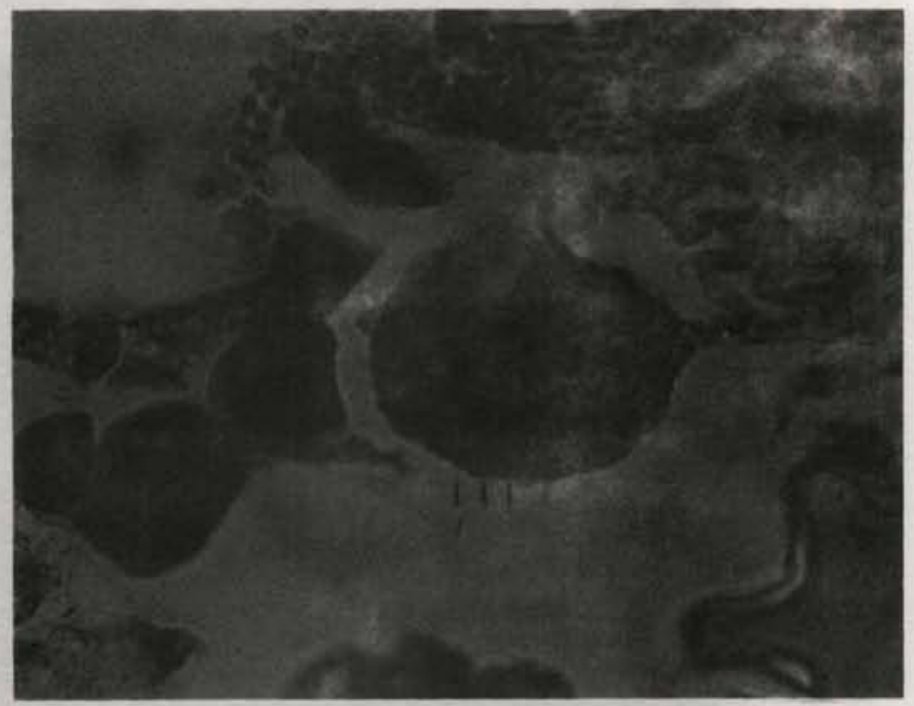

Fig. 4. III = foliculo ovariano com inicio de vitelogênese lipídica. $\mathrm{VL}=$ va- . cúolos lipídicos; $\mathrm{N}=$ núcleo; $\mathrm{Nc}=$ nucléolos; $\mathrm{C}=$ citoplasma (40×10).

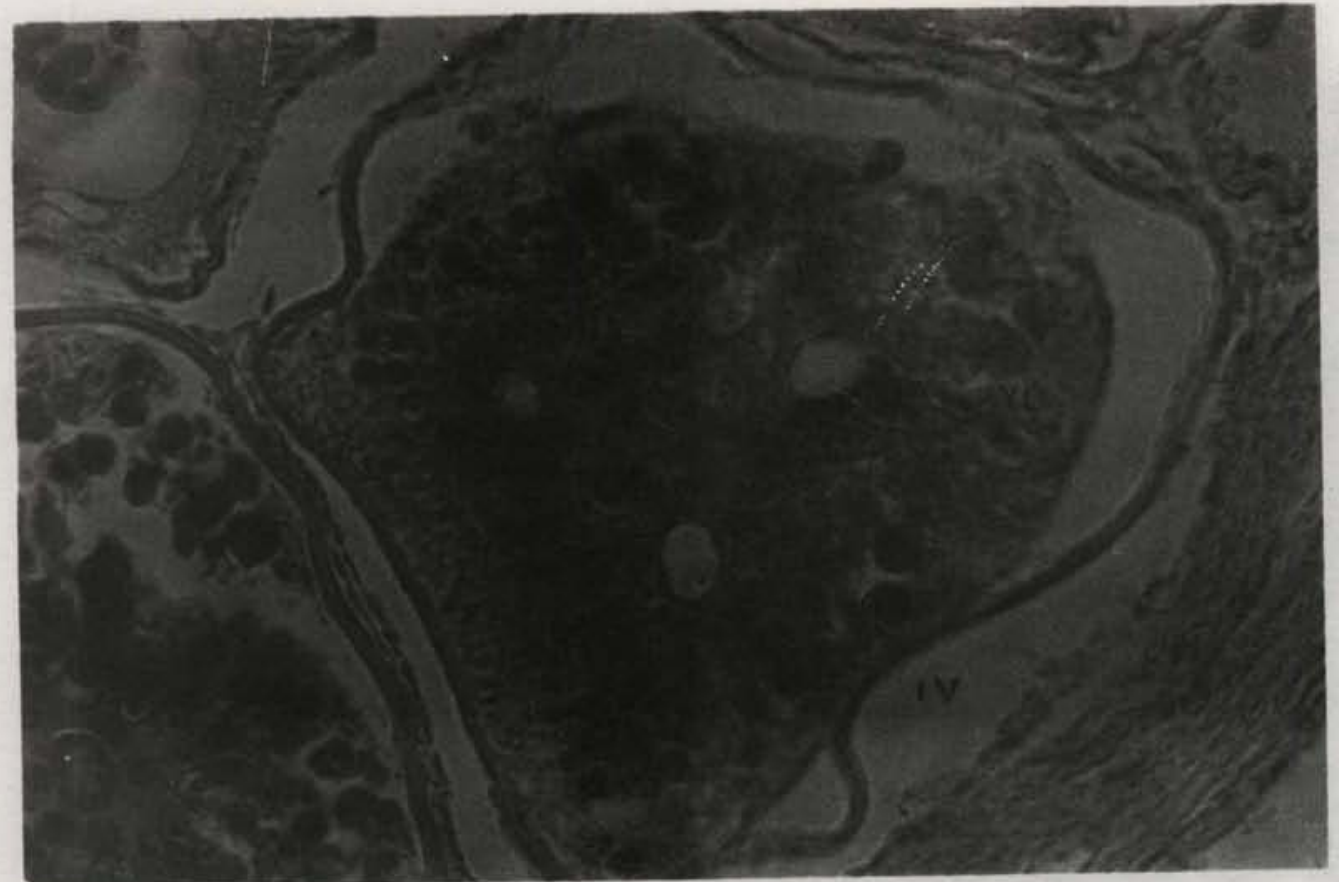

Fig. 5. IV = folículo com vitelogênese lipídica e proteíca. $\mathrm{VI}=$ vacúolos lipidicos; $\mathrm{Gp}=$ grânulos protelcos; $\mathrm{Mv}=$ membrana vitelina; $\mathrm{Cf}=$ células foliculares (40x10). 


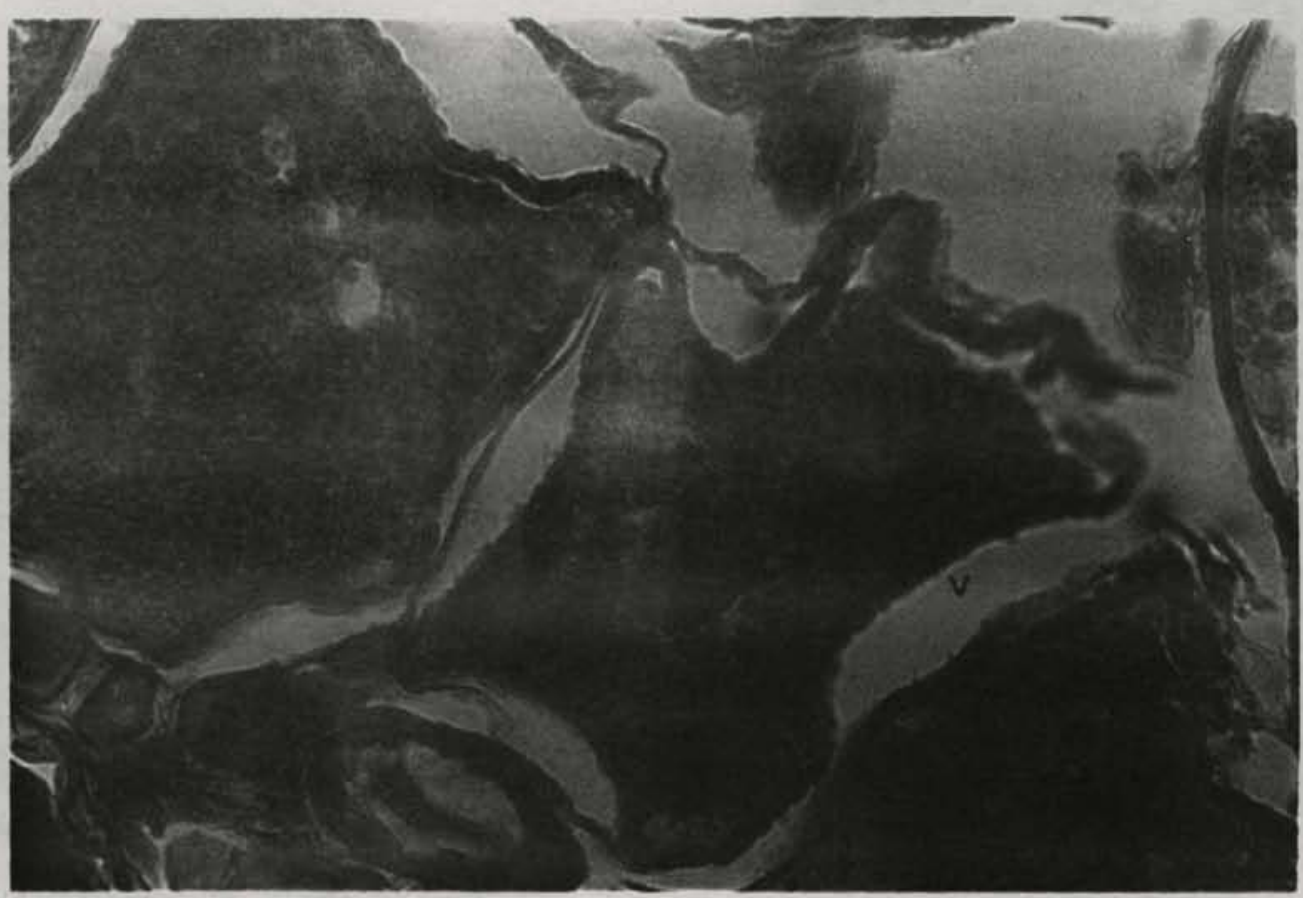

Flg. 6. $V=$ foliculo com vitelogênese completa. $C=$ cltoplasma; $N=$ núcleo; GLP = grânulos lipoprotélicos $(40 \times 10)$.

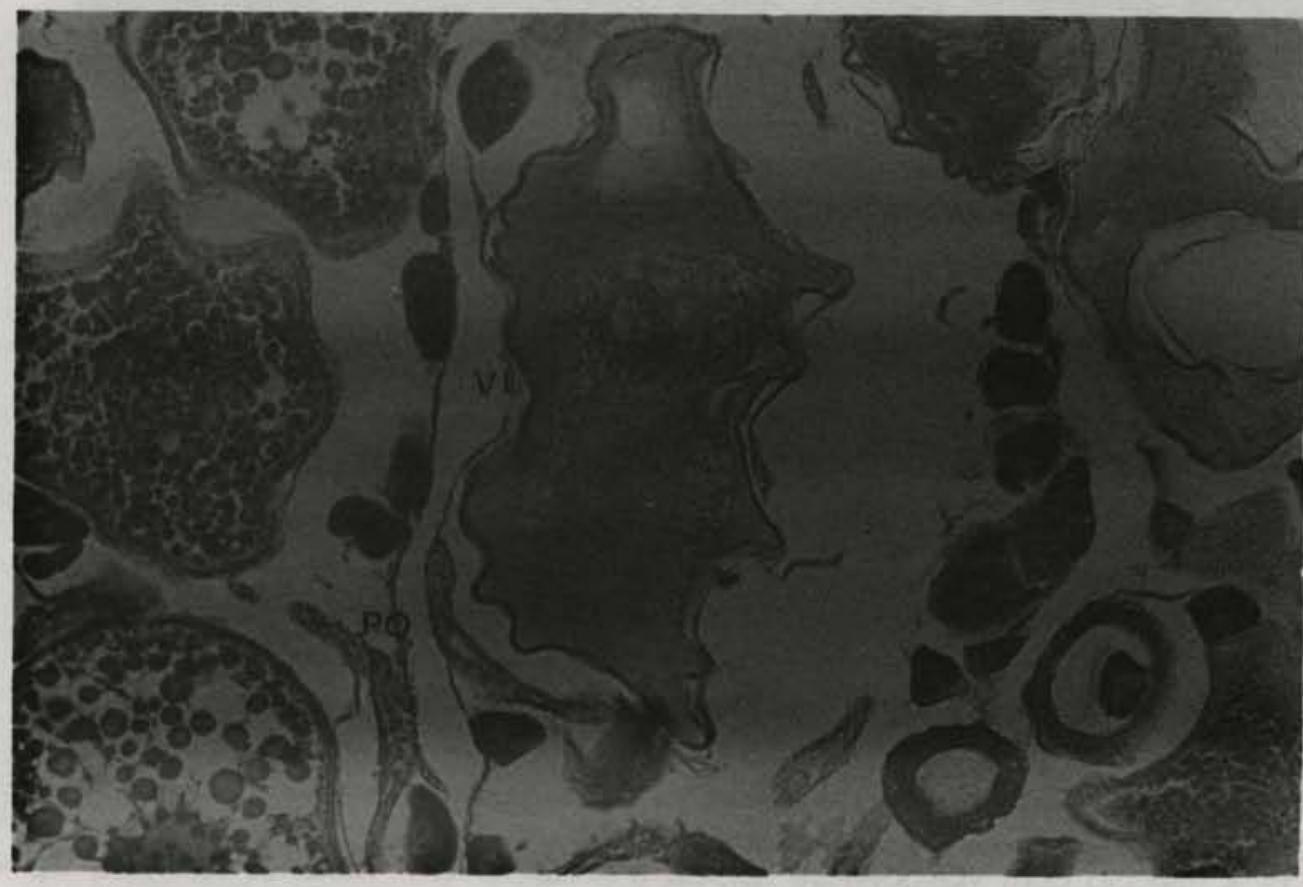

Fig. 7. $V=$ foliculo hidratado; $C=$ citoplasma; $P O=$ foliculo pós-ovulatório (16x10). 
De acordo com estudos de Naumov (1956) a presença de ovócitos em fases de desenvolvimento intermediário entre imaturo e maduro no ovário de um mesmo peixe indica que a desova é parcelada. Esta definiçẫo foi complementada por Barbieri et al. (1981), através de observaçōes histológicas nos ovários de $G$. brasiliensis, onde verificaram a presença de ovócitos em diferentes fases de desenvolvimento em um mesmo corte, sugerindo desova do tipo parcelada para esta espécie, e por Chaves (1988), após ter verificado que dentre as 80 espécies citadas em seu trabalho, 61 apresentam um desenvolvimento ovocitário assincrônico ou sincrônico em mais de dois lotes, tendo estas provável desova múltipla.

Peres et al. (1991) verificaram que $E$. longimanus, capturado no litoral norte do Estado de São Paulo, apresentou início do desenvolvimento ovocitário caracterizado por uma basofilia citoplasmática, sem a presença de substâncias nutritivas, e o início da vitelogênese caracterizada pelo acúmulo de vacúolos lipídicos ao redor do núcleo e grânulos de vitelos protéicos na periferia citoplasmática. A constatação de desova foi indicada pela presença de folículos hidratados e folículos pós-ovulatórios, encontrados em cortes de um mesmo ovário. Assim, foi sugerido que $E$. longimanus apresenta um desenvolvimento ovocitário assincrônico.

O termo "desenvolvimento assincrônico", segundo Wallace \& Selman (1981), diz respeito à maturaçāo contínua dos ovócitos, sem formação de lotes distintos, como ocorre em um desenvolvimento sincrônico em apenas dois grupos. Segundo Blaxter \& Hunter (1982) e Chaves (op. cit.) esta terminologia pode ser empregada como sinonímia do desenvolvimento sincrônico em mais de dois lotes ovocitários, que, normalmente, originam desova múltipla ou parcelada.

As distribuiçōes mensais da freqüência de classes de comprimento padrão evidenciaram a ocorrência de duas classes modais: a primeira representada por indivíduos menores que $75 \mathrm{~mm}$, considerados jovens, e a segunda representada por individuos com comprimentos iguais ou acima de $75 \mathrm{~mm}$, considerados adultos. Constatou-se que de novembro de 1986 a maio de 1987 foram capturados, predominantemente, adultos. Dejulho a setembro de 1987 verificou-se a presença das duas classes modais, porém com maior incidência de indivíduos jovens. A partir de outubro inicia-se, novamente a predominância de exemplares adultos, até abril de 1988 . Em maio os jovens retornaram às amostragens, sendo capturados com maior freqüência até setembro de 1988 (Fig. 8).

A análise da distribuição de freqüência dos estádios de maturaçāo indica a captura de indivíduos nos estádios C (maduro) e D (com indícios de desova), principalmente nos meses de outubro a março de 1986, 1987 e 1988. Grande incidência de exemplares no estádio A (imaturo) foi verificada a partir de abril até setembro, seguindo-se sua diminuição e o aumento progressivo de indivíduos no estádio B a partir de outubro (Fig. 9).

A análise da distribuição temporal dos valores da $\overline{\text { RGS }}$ evidencia que os valores mais altos ocorrem nos meses de novembro, dezembro e janeiro, com oscilaçōes em níveis mais baixos no restante dos períodos. Nos meses de maio e junho de 1987, como em fevereiro, maio, junho e agosto de 1988, não registrados os valores de RGS por se tratarem de espécimes jovens (abaixo de $75 \mathrm{~mm}$ ) ou por estarem com ovários em maturação inicial ou em recuperaçāo (Fig. 10).

Os resultados obtidos indicam que a desova ocorreu desde o fim da primavera, atingindo picos máximos no verão, até o início do outono (outubro a abril).

Kawakami (1979), estudando a bionomia e biologia de Syacium papillosum na plataforma continental entre Cabo Frio e Torres, verificou que esta espécie desova desde o final da primavera (novembro) ao inf́cio do outono (abril), com maior intensidade no verão (janeiro-fevereiro), ao longo dessa área, não apresentando um local de desova específico. Entretanto, observou-se na regiāo de Cabo Frio, que a desova ocorreu predominantemente no verão, com a temperatura variando de $15^{\circ}$ a $18^{\circ} \mathrm{C}$, época do fenômeno da ressurgência na região.

Os gráficos das distribuiçōes mensais dos valores de temperatura média e RGS de fêmeas adultas de $E$. longimanus mostram que há uma relação inversa entre temperatura e RGS, sendo que os maiores valores desta relação verificaram-se nos meses em que a temperatura é mais baixa (Fig. 11).

O fenômeno da ressurgência na regiāo de Cabo Frio foi largamente estudado por Kempf et al. (1974), que relataram que o relevo, as condiçöes hidrológicas e os ventos E-NE provocam, em razão do desvio de Coriolis, um afastamento da Corrente do Brasil em relação à costa, fazendo com que haja uma ressurgência de águas profundas e ricas em nutrientes provenientes da Corrente das Malvinas. Complementando este estudo, Valentin et al. (1978) realizaram um trabalho sobre o perfil térmico desta regiảo, mostrando a ocorrência de uma sucessāo de fases em relação a temperatura da água. 0 fenômeno da ressurgência, ou época de estabilidade fria, provoca uma homotermia em toda coluna d'água, com a temperatura em torno de $14^{\circ} \mathrm{C}$, ocorrendo principalmente, no verăo.

Os resultados encontrados neste trabalho e em Kawakami (op. cit.), demonstram que a época de desova de $E$. longimanus $\mathrm{e} S$. papillosum, na regiẩo de Cabo Frio, ocorre, principalmente, na época de ressurgência, com valores baixos de temperatura. Segundo Agostinho (1979) o processo reprodutivo sofre influência de fatores exógenos, citando que o aumento da temperatura estimula ou antecipa a época de desova, porém, em casos como estes, provavelmente, fatores como alta bioprodutividade e riqueza de nutrientes são mais relevantes para o estímulo da reproduçäo, como foi verificado por Valentin (1983), que relatou que o enriquecimento das águas da regiāo de Cabo Frio na época de ressurgência tem sido manifestado pela super produção de fito e zooplâncton, grande abundância de moluscos bivalves, especialmente da espécie Perna perna, grande reprodução de bancos de Laminaria brasiliensis e $L$ abyssalis, alem de intensa produção de Sardinella brasiliensis. 


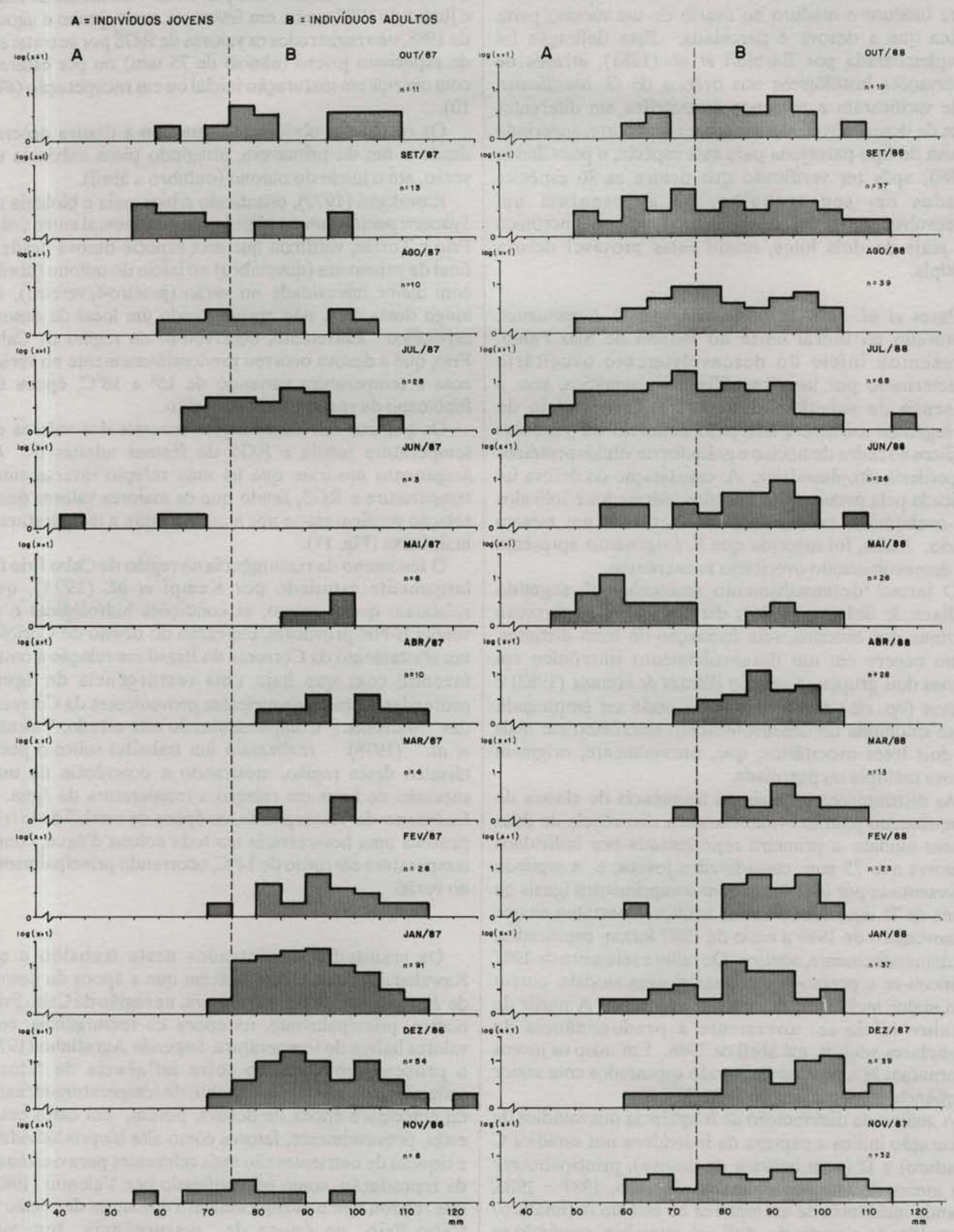

Fig. 8. Distribuição mensal das freqüências $[\log (x+1)]$ das fêmeas de $E$. longimanus por classe de comprimento padrăo, durante o período de novembro de 1986 a outubro de 1988. 


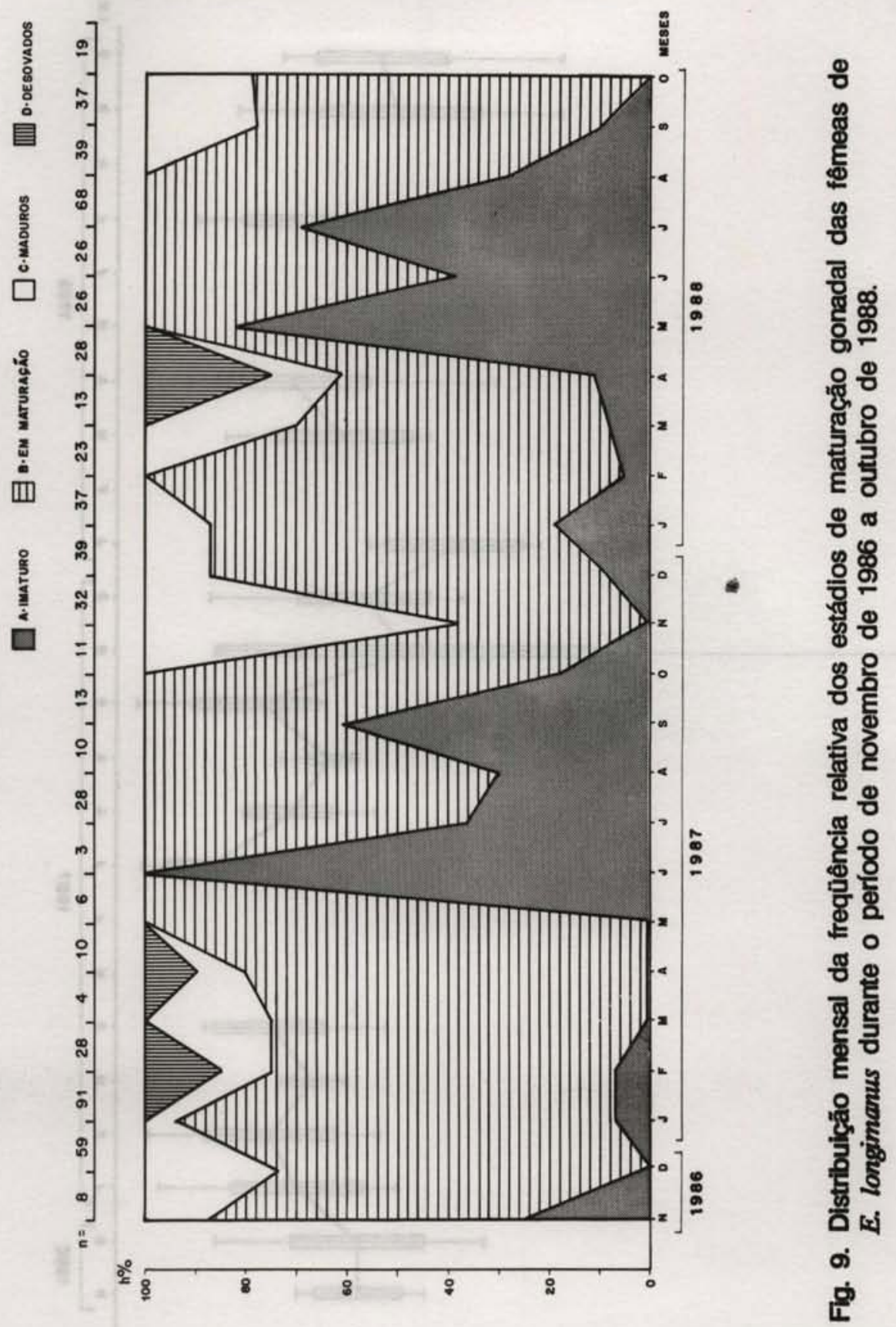




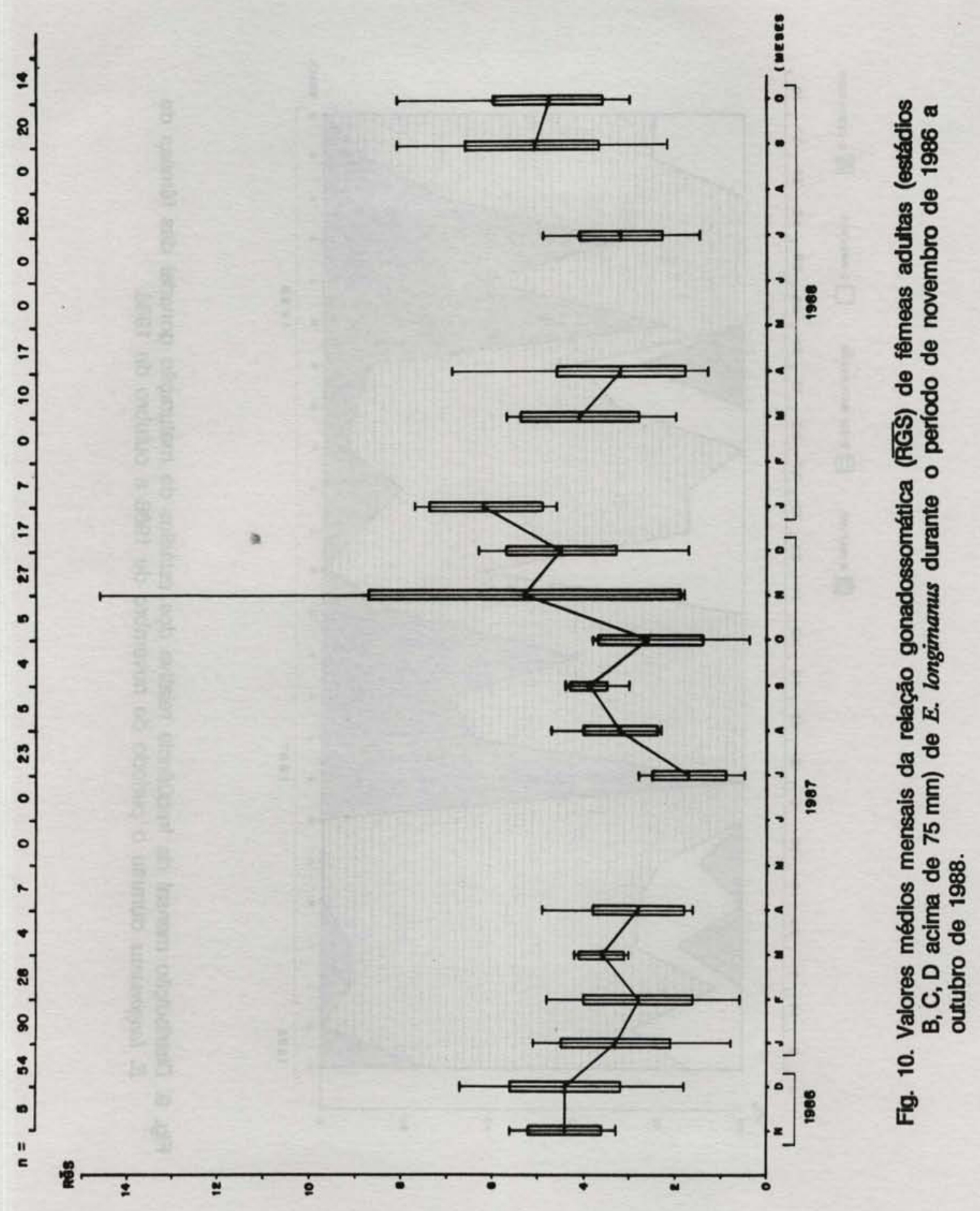




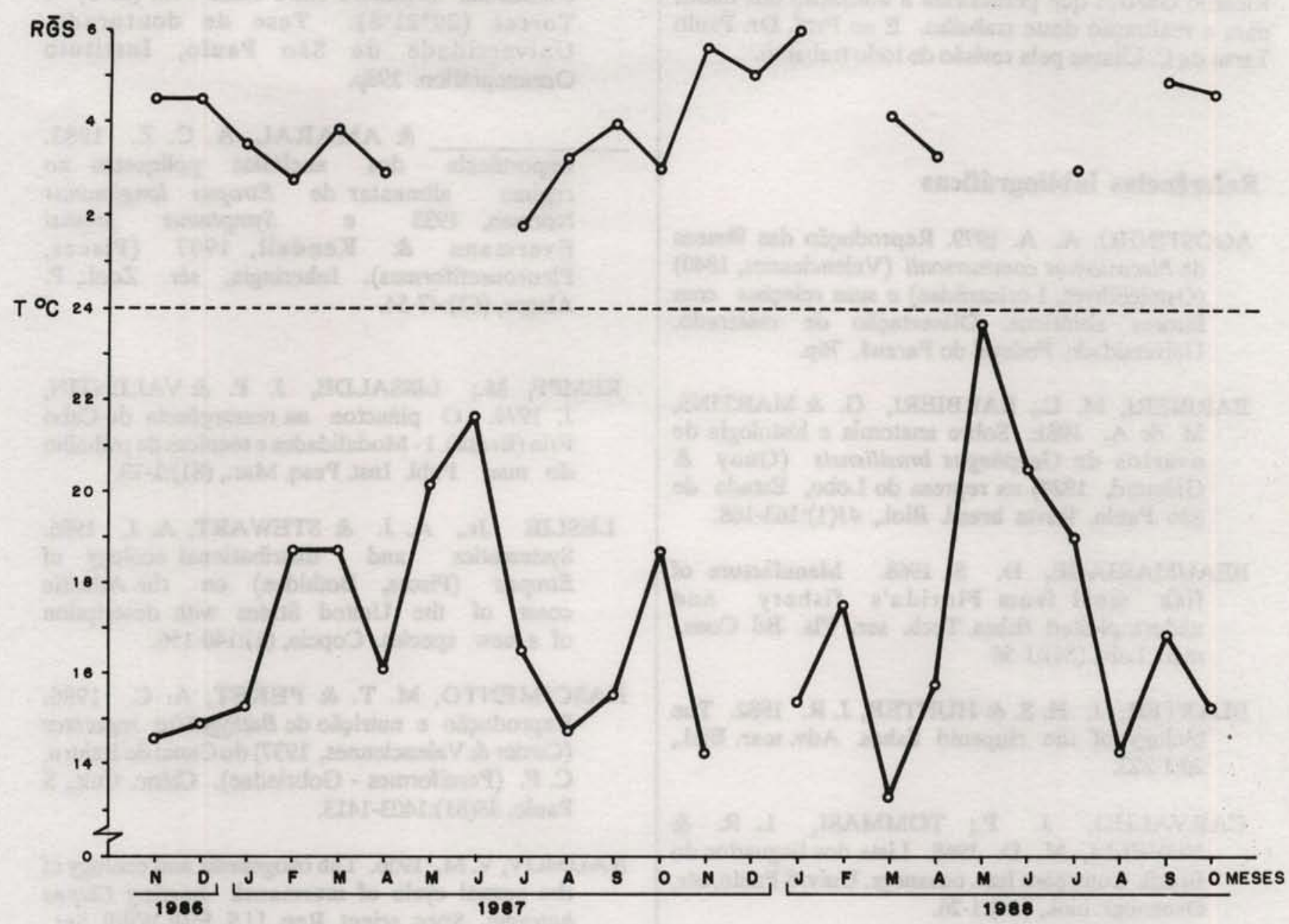

Fig. 11. Distribuição mensal dos valores médios da temperatura (estações 30,45 e $60 \mathrm{~m}$ ) e distribulção mensal do $\overline{\text { RGS }}$ das fêmeas adultas de $E$. longimanus da regiăo de Cabo Frio.

\section{Resumo}

Durante o período de novembro de 1986 a outubro de 1988 foram realizados estudos sobre a ictiofauna demersal na regiāo de ocorrência do fenômeno da ressurgência em Cabo Frio, pelo Instituto de Estudos do Mar Almirante Paulo Moreira (IEAPM).

A partir de coletas mensais da ictiofauna, efetuadas com arrasto de porta, e da água, para a obtenção dos valores da temperatura, constatou-se a abundância de Etropus longimanus na regiāo. Foram obtidas 653 fêmeas, em diferentes tamanhos e fases de desenvolvimento gonadal, o que nos permitiu a realização de um estudo sobre alguns aspectos da biologia reprodutiva desta espécie, como o tamanho da primeira maturação, o tipo de desova e a época de reprodução na regiāo. Estimou-se um comprimento padrão médio em que a população das fêmeas apresentam $50 \%$ de probabilidade de estarem sexualmente maduras, de $75 \mathrm{~mm}$; e o comprimento padrão médio em que todas estão aptas à reprodução, de $95 \mathrm{~mm}$. Verificou-se que $E$. longimanus apresenta um desenvolvimento ovacitório sincrônico em mais de dois grupos, sugerindo a ocorrência de desova múltipla. Os resultados obtidos indicaram que a desova ocorreu desde o final da primavera, até o início do outono, com picos máximos no verāo, quando registrou-se os valores da temperatura da água entre $13,3^{\circ} \mathrm{C}$ a $18.7^{\circ} \mathrm{C}$, época predominante de ressurgência na regiāo.

\section{Agradecimentos}

Adriana Miguel Saad gostaria de agradecer ao Prof. Dr. José V. Andreata da Universidade Santa Úrsula pela 
orientação da monografia da qual este trabalho faz parte. Agradecemos ao Instituto de Estudos do Mar Almirante Paulo Moreira (IEAPM) e ao Biólogo Ricardo Gaelzes que permitiram a utilizaçāo dos dados para a realizaçäo deste trabalho. E ao Prof. Dr. Paulo Tarso da C. Chaves pela revisão de todo trabalho.

\section{Referências bibliográficas}

AGOSTINHO, A. A. 1979. Reprodução das fêmeas de Plecostomus commersonii (Valenciennes, 1840) (Osteichthyes, Loricariidae) e suas relaçöes com fatores abióticos. Dissertação de mestrado. Universidade Federal do Paraná. 76p.

BARBIERI, M. C.; BARBIERI, G. \& MARTINS, M. de A. 1981. Sobre anatomia e histologia de ovários de Geophagus brasiliensis (Quoy \& Gaimard, 1824) na represa do Lobo, Estado de São Paulo. Revta brasil. Biol, 41(1):163-168.

BEAUMARIAGE, D. S. 1968 . Manufacture of fish meal from Florida's fishery and underexploited fishes. Tech. ser. Fla. Bd Cons. mar. Lab., (54):1-56

BLAXTER, J. H. S. \& HUNTER, J. R. 1982. The biology of the clupeoid fishes. Adv. mar. Biol., 20:1-223.

CARVALHO, J. P.; TOMMASI, L. R. \& NOVELLI, M. D. 1968. Lista dos linguados do Brasil. Contrçōes Inst. oceanogr. Univ. S Paulo, sér, Oceanogr. biol., (14):1-26.

CASTRO FILHO, B. M. de; MIRANDA, L. B. de \& MIYAO, S. Y. 1987. Condiçōes hidrológicas na plataforma continental ao largo de Ubatuba: variaçōes sazonais e em média escala. Bolm Inst. oceanogr., S Paulo, 35(2):135-151.

CHAVES, P. T. C. 1988. Aspectos convergentes da dinâmica ovariana nos peixes, com uma contribuição à biologia reprodutiva de 14 espécies do litoral de São Paulo. Tese de doutorado. Universidade de São Paulo, Instituto Oceanográfico. 123p.

1989. Hidratação pré-ovulatória em peixes: um caráter de origem marinha? Revta brasil. Zool., 6(3):463-472.

ISAAC-NAHUM, V.J.; VAZZOLER, A. E. de M. \& ZANETI-PRADO, E. M. 1983. Estudos sobre estrutura, ciclo de vida e comportamento de Sardinella brasiliensis (Steidachner, 1979) na área entre $22^{\circ} \mathrm{S}$ e $28^{\circ} \mathrm{S}$, Brasil. 3. Morfologia e histologia de ovários e escala de maturidade. Bolm Inst. oceanogr., S Paulo, 32(1):1-16.
KAWAKAMI, E. 1979. Estudo da distribuição, estrutura, biologia e bionomia de Syqcium papillosum (Linnaeus, 1758), na plataforma continental brasileira entre Cabo Frio $\left(23^{\circ} \mathrm{S}\right)$ e Torres $\left(29^{\circ} 21^{\prime} \mathrm{S}\right)$. Tese de doutorado. Universidade de São Paulo, Instituto Oceanografico. 198p.

\& AMARAL, A. C. Z. 1983. Importância dos anelídios poliquetos no regime alimentar de Etropus longimanus Norman, 1933 e Symphunus jenynsi Evermann \& Kendall, 1907 (Pisces, Pleuronectiformes). Inheringia, sér. Zool., P. Alegre, (62):47-54.

KEMPF, M.; LISSALDE, J. P. \& VALENTIN, J. 1974. O plâncton na ressurgência de Cabo Frio (Brasil). I-Modalidades e técnicas de trabalho do mar. Publ. Inst. Pesq. Mar., (81):1-13.

LESLIE Jr., A. J. \& STEWART, A. J. 1986. Systematics and distributional ecology of Etropus (Pisces, Bothidae) on the Atlantic coast of the United States with description of a new species. Copeia, (1):140-156.

NASCIMENTO, M. T. \& PERET, A. C. 1986. Reprodução e nutrição de Bathygobius soporator (Cuvier \& Valenciennes, 1937) do Canal do Itajuru, C. F. (Perciformes - Gobriedae). Ciênc. Cult., S Paulo, 38(81):1403-1413.

NAUMOV, V. M. 1956. The ovogenesis and ecology of the sexual cycle of murmansk herring Clupea harengys. Spec. scient. Rep. U.S. Fish Wildl. Ser., Fisheries, (327):203-263.

NIKOLSKY, G.V. 1963. The ecology of fishes. London, Academic Press. 352p.

NORMAN, J. R. 1933. Notes on Heterosomata. V. Four new species from the Atlantic coast of America. Ann. Mag. nat. Hist., ser. 10:201-204.

PERES, E.; FERRAZ DIAS, J.; NISHIYAMA, S. M.; LOBO, S. \& ROSSI-WONGTSCHOWSKI, C. L. D. B. 1991. Desenvolvimento ovocitário dos linguados Paralichthys patagonicus, Etropus longimanus e Etropus crossotus, famflia Bothidae. In: ENCONTRO BRASILEIRO DE ICTIOLOGIA, 9., Maringá, 1991. Resumos. Maringá, Sociedade Brasileira de Ictiologia Universidade Estadual de Maringá. p.60.

VALENTIN, J. 1983. L'écologie du plancton dasn la remontée de Cabo Frio (Brésil). Thése de Docteur en sciences. Université d'Aix-Marseille II, Faculté des Sciences de Luminy. 
VALENTIN, J.; ANDRE, D. L.; MONTEIRO RIBAS, W. M. \& TENENBAUM, D. R. 1978. Hidrologia e plâncton da regiāo costeira entre Cabo Frio e o estuário do Rio Parába (Brasil). Publ. Inst. Pesq. Mar., (127):1-24.

VAZZOLER, A. E. A. de M. 1981. Manual de métodos para estudos biológicos em populaçōes de peixes. Reprodução e crescimento. Programa Nacional de Zoologia. Brasília, CNPq. 106p.

; SILVEIRA, M. M. C.; SANTORO-MAZAGÃO, E. C. \& LIZAMA, M. A. P. 1989. Estrutura dos estratos populacionais de Pleuronectiformes em ecossistema tropical costeiro do Estado de São Paulo. In: SIMPÓSIO SOBRE OCEANOGRAFIA - IOUSP, 1., São Paulo, 1989. Resumos. São Paulo, Instituto Oceanográfico da Universidade de São Paulo. p.73.
WALLACE, R. A. \& SELMAN, K. 1981. Cellular and dynamic aspects of oocyte growth in teleosts. Am. Zool., 21:325-343.

(Manuscrito recebido 3 de Junho 1991; revisto 16 Dezembro 1991; aceito 8 Outubro 1992) 